\title{
ICT BASED AGRO-ADVISORY SERVICES IN NEPAL
}

\author{
R. Paudel ${ }^{1 *}$, P. Baral ${ }^{2}$, S. Lamichhane ${ }^{2}$ and B.P. Marahatta ${ }^{2}$ \\ ${ }^{1}$ Drectorate of Extension (DoE), Institute of Agriculture and Animal Science, Tribhuvan \\ University, Nepal \\ ${ }^{2}$ Institute of Agriculture and Animal Science, Tribhuvan University, Nepal \\ *rajesh@iaas.edu.np
}

\begin{abstract}
The world has already witnessed the rapid surge in use of Information Technology (IT) in agriculture and understands its effectiveness through the miracles we have achieved. In such context, agriculture extension and advisory service in Nepal can be heavily boosted with the help of most effective and affordable information and communication technologies (ICTs). With smartphones, internet services, mobile networks, televisions and radio widespread all over the country, they can prove to be a promising means for dissipation of information in rapidly altering and modernizing farming system of Nepal. This paper aims to explore the current scenario, role and effectiveness of ICTs in agro-advisoryservices of Nepal and to point out salient issues hampering the development of ICT. Information and findings are based on available literature, articlesand publications and they suggest that ICTs can play a crucial role in linking extension, research and farmers and in the overall development of agriculture especially in the context of developing country like Nepal. The potential contribution of ICT in agriculture extension is still fully unexplored and they can be effective means for providing timely and relevant information to farmers residing in every corner of the country.
\end{abstract}

Key Words: Information and Communication Technologies (ICTs), Agriculture extension, Agro-advisory service

\section{INTRODUCTION}

The agriculture is often subjected to world forces and changes such as new discoveries and technologies, demographic change, change in socio-economic structure, consumption patterns and interdependence in global markets (Suvedi \& Kaplowitz, 2016). In response to these changes, the importance on generation and application of agriculture-related knowledge is increasing as the farmers, especially small and marginal need relevant information so as to improve their farming enterprises and diversify and sustain them (Glendenning \& Ficarelli, 2012). However, there exists sluggish and stagnant growth in agriculture owing to the need of dynamic, innovative and vibrant approach for the agriculture extension and advisory service providers to adopt so as to flourish agriculture coping with these changes so as to serve farmers and achieve targeted growth rate (Saravanan, 2012).

The important role of extension relies on delivering the information, suggestions, knowledge and advice to the farmers. However, a major challenge exists for this service in being relevant to changing situations and for this, it needs to specialize in effectively managing and transferring knowledge and information packages to farmers. The philosophy and rationale of the extension services have been changed and is shifting towards participatory development and development towards extension plus i.e. the extension and advisory services (Oladele, 2015).

Looking at the context of Nepal, the agriculture extension and advisory service have been gradually changing over time. Originally performed by the government and public sectors, however similar to the scenario of many developing countries as mentioned by Swanson (2009), Nepal also has not been able to benefit from that government-led extension services as expected. This led to the 
need for reorganizing the extension services that resulted in decentralized and devolved extension and advisory service delivery at lower levels of administration. With time, there evolved the market/ demand driven and pluralistic approaches to extension service delivery. At present context, the issues of privatized and ICT based advisory services are gaining light in Nepal.

Information and knowledge are central components of agricultural development (Munyua, 2007). The statement of FAO (2000) asserts "information and knowledge play a key role in ensuring food security and sustainable development." In this sense, it has been recognized that the extension and advisory services should be incorporated with the Information and Communication Technologies (ICTs). They are the key enablers of globalization and allow for the cost-effective and efficient flow of information, products, people and capital across the globe (Oladele, 2015). This concept, when incorporated in agriculture advisory services is believed to boost agriculture development by enhancing the information accessibility of the farmers so that they would make the best decisions and use their resources sustainably. The application of information and communication technologies (ICTs) could benefit agriculture, especially in bringing changes in the socioeconomic conditions of the poor in rural areas. (Singh et al., 2015).

The high ratio of extension personnel: farmers' household ratio (1:1333) and only $15 \%$ extension service coverage (Krishi Diary, 2016) has resulted in not so satisfactory extension and advisory service delivery in Nepal and the location and access of extension agent appear to be constraint for farmers to receive relevant advice regarding their farm problems in remote areas. The ICT based agro-advisory services tend to solve this problem by providing cost-effective advisory services to farmers through ICT tools like radio, television, call centers, mobile applications etc. whenever required by them regardless of the limitations caused by accessibility and availability of extension personnel. With the radical change in the information ecosystem through wide mobile coverage across the country, it has created space for more information and ICTs have been proved to be a significant indicator for development of different sectors including agriculture; where these technologies are acting to enhance agricultural production through the introduction of farm technologies (Das, 2016).

In this context, this paper tends to conceptualize the agriculture extension and advisory service and highlight the significance of ICT based agro-advisory service in Nepalese agricultural context. The paper also points the initiatives taken in Nepal regarding ICT use in agriculture in Nepal and discusses its effectiveness, social impact and constraints faced. Finally, the paper presents a simplified model showing ICT based agro-advisory service use in Nepal.

\section{METHODOLOGY}

This article is based on different review papers, journals, book chapters and theses.

\section{RESULTS AND DISCUSSION}

\section{Agriculture extension and advisory service: A brief concept}

For enhancing the agriculture production and promotion of agriculture development, agriculture extension and advisory services have long been recognized to be a significant factor (Anderson $\&$ Feder, 2007). In this regard, the role of extension and its effectiveness in the future is in need of acknowledgment. The terms 'agriculture extension' and 'agro-advisory services' refer to 'the entire set of organization that support and facilitate people engaged in agricultural production to solve problems and obtain information, skills and technologies to improve their livelihoods.' (World Bank, 2007).Often used interchangeably, the terms extension and advisory services make a framework consisting the approaches based on 4 paradigms as mentioned by Swanson (2009), which are: 
- Technology transfer, persuasive and paternalistic top-down approach focused on increasing food production by persuading farmers for adopting new technologies that are cost effective.

- Advisory services, persuasive and participatory approach often comprising pluralistic method involving public and private extension agents, farmers are advised to use specific practice or technology in response to identified problem and constraints, validated through research.

- Non-formal education, educational and paternalistic approach focused on training farmers to utilize the specific management skills and technical knowledge for production efficiency.

- Facilitation extension, educational and participatory approach focusing to help farmers define their own problems and develop their own solutions.

Being an agriculture-dependent country, Nepal has to lay its focus on effective and efficient agro-advisory service delivery to its farmers so as to enhance agriculture development. However, the traditional method of extension and advisory service deliveries are not effective enough. In this regard, the ICT based agro-advisory service emerges as a viable alternative. Looking at the extension service delivery in Nepal, the extension service coverage is only 15\% (Krishi Diary, 2016) and there exists a gap between extension agents and farmers which is found to be in increasing trend. The extension agent: household ratio also seems to be higher, 1: 1333 (MoAD, 2017). This high ratio has become a prime cause for ineffective extension and advisory service delivery. The location and access of extension agents have also caused limitations for providing suitable advice to farmers of remote areas regarding their farm problems. The ICT based agro-advisory services tend to solve this problem by providing cost-effective advisory services to farmers through ICT tools like radio, television, call centers, mobile applications etc. whenever required by them regardless of the limitations caused by accessibility and availability of extension personnel. With the radical change in the information ecosystem through wide mobile coverage across the country, it has created space for more information; though challenge lies in ensuring equal access to information to all and enabling farmers make advantageous decisions. Still there exists lack of research, viable information and supportive policy environment for the effectiveness of ICT based agro-advisory services. Today's world is the era of information and technology. The ICTs have been proved to be a significant indicator for the development of different sectors including agriculture; where these technologies are acting to enhance agricultural production through the introduction of farm technologies (Das, 2016). In this context, Nepal is also accelerating its efforts in using ICT for agriculture development and advisory services.

\section{ICT and its use in agriculture}

Information and communication have always mattered in agriculture (Singh, 2014). Since the primitive era of practicing agriculture, there have been sharing of information among people from one another; may it be crop raising, livestock, poultry or fish farming. However, looking at the changing context of today's world with the emergence of new severe challenges, the introduction of Information and Communication Technology is a primary need which is well timed for solving those challenges. With the increase in the coverage of modern ICT tools like mobiles, wireless, internet services along with the modernization of traditional ICT tools like radio, television, printed media; these tools are playing a significant role in boosting agriculture production and development with pluralistic approach engaging both public and private sectors (Singh, 2014).

Agricultural knowledge is very important for small and marginal farmers. They require relevant and contemporary information regarding agriculture and the widespread ICT are enhancing the information flow in the farming community. They are facilitating the creation, management, 
storage, retrieval and dissemination of the relevant data and information that may have been required and adapted (Heeks, 2002). Looking back to some decades, television and radios were major tools for disseminating technologies, however the context has been changed and these days internet and mobile-based smart ICTs are being widely used in form of social media, digital photography and video, digital information repositories etc. in disseminating agriculture related information and technologies to rural communities (Balaji, Meera\& Dixit, 2007). However, ICTs have been facing the problems of sustainability, affordability, ease of use, accessibility, scalability and availability of relevant content in appropriate language (Saravanan, 2010), though the effective accessibility, applicability and delivery of content might increase the ICT use by farmers which might be significant for enhancing agriculture (Singh, 2014).

The obvious cross-cutting way that ICT can improve agriculture in Nepal is the improved accessibility to the information, making it cost-effective to obtain and adapt (FAO, 2017). With the wide mobile coverage and radical change in information ecosystem, the equal access to knowledge and information is being ensured and the confusion and dilemma in farmers are being sorted out through adaptation of ICTs (Regmi, 2016). Also, the main advantage of ICT tools for agriculture is that the targeted customers could be reached in a matter of minutes. Although being a relatively new phenomenon, ICT has been contributing to food security and poverty alleviation. The trend of using mobiles for exchanging and sharing information on farming began with the practice of sending and receiving text messages. Some government offices are already using SMS based information sharing platforms on their network. The SMS platform is efficient as, short messages, the mobile application can be used to get/share large quantities of agro-information at a low cost. With network (voice and data) coverage of more than $90 \%$ throughout the country and smartphones being more affordable, we can expect more smartphone penetration among farmers. At present, the number of smartphone users has already reached 4.5 million in Nepal.

\section{ICT based agro-advisory services provided by the government and private agencies in Nepal}

Das (2016) highlighted mainly following five initiatives of ICTs in agro-advisory services provided different private and public agencies that are equally applicable in Nepal with some existing illustrations.

- Telecommunication initiatives: Farmers' call center by AICC for receiving and solving farmers problem with the help of agriculture experts, SMS service about the market price related information on agriculture commodities by Kalimati and DoA.

- Media initiatives: Agriculture related programs like KrishiSamachar, KrishiKaryakram on national television and FM radios broadcasting information related to contemporary issues and technologies in agriculture.

- Printed media: Krishi diary, Bimonthly magazines, booklets and pamphlets by AICC, Nepal; KrishakPana in national magazines like Kantipur highlighting specific commodities and issues.

- Internet-based initiatives: Smart Krishi, IBA Krishi, mobile applications and other agriculture online portals of DoA, AICC providing information related to agriculture.

- Agro-meteorological initiatives on the weather forecast and cropping pattern using GIS, GPS services.

Project for Agriculture Commercialization and Trade (PACT) and Agriculture Management Information System (AMIS), under the MoAD, among other governmental organizations, are working to increase the access of farmers to mobile applications. PACT has recently developed three different kinds of apps which will allow field verification of sub-projects, monitoring and checking details of subsidized sub-projects via GPS in mobiles. Agricultural apps like "Smart Krishi”, "Krishi Ghar" and 
IFA Krishi are some projects initiated by the private sector for sharing information related to farming technologies, livestock, pest, weather, market price and even interaction with prospective buyers. The most trending application with a considerable pool of information, Smart Krishi alone hauled in more than 7,500 users in the first 6 months of its launch. Smart Krishi has made it easier to get into agro-entrepreneurship by providing every relevant genuine information (from initial planning to post harvesting/storage techniques) about professional farming for free of cost (Regmi, 2016).

\section{Effectiveness of ICT based agro-advisory services in addressing information need of farmers}

The access of required information and knowledge heavily relies on ICT in the present context (Richardson, 1997) and its use was highly effective in agriculture-related projects in India resulting in good performance of the projects with social and economic change (Kaushik \& Singh, 2004). Meera, Jhamatiand Rao (2004) highlighted the significance of ICT in gathering, storing and disseminating information among farmers. The faith in people and their orientation towards ICT are also found to be logically associated with their personal effectiveness. ICT use, reducing the information search cost, dramatically lowers the transaction costs and enables greater farmer participation in commercial agriculture (Silva \& Ratnadiwakara, 2008). Similarly, ICT based agro-advisory has a positive impact on sustainable poverty reduction. Sugahara (2009) found that ICT use has helped in the use of modern farm equipment and agriculture processes like harvesting, transporting, labeling and preserving more efficiently. Similarly, Mittal, Gandhi andTripathi (2010) also highlighted the effectiveness of ICT based agro-advisory in successful fish production in Bangladesh.

\section{Socio-economic Impacts of ICT based agro advisory services}

Cecchini and Scott (2002) reported that ICT can reduce rural poverty by increasing their access to education, health, governmental and financial services. It connects small farmers to market and isbudget and practical tools for facilitating information delivery and knowledge sharing among farmers, extension agents and stakeholders. The widespread ICT agro-advisory services also help in reducing risk and uncertainties among farmers making them more innovative and competent (Abraham, 2007).

Best and Maiyer (2007), in a study, suggested that no any significant relationship exists in ICT based agro-advisory service use and education level of farmers. However, in another study by Ali and Kumar (2010), where comparative analysis between ICT users and non-users in agriculture extension services was done, it was found that education, social categories, income, land holdings etc. were affecting the decision making in ICT use among farmers.

Wankhade, Khare and Dhruv (2011) stated that the mobile applications were playing an effective and positive role for technology transfer in terms of cost-effectiveness and solving fieldbased problems of farmers.

\section{Constraints faced by ICT based agro-advisory services}

Mansell and When (1998) stated that illiteracy is the main barrier for the effectiveness of ICT based agriculture extension since a large proportion of the rural population are illiterate, lacking basic skills required for utilizing the benefits of ICTs. Similarly, relevancy in content and local language are also a barrier for adoption of ICT based agro-advisory services (Munyua, 2007). Also, farmers' inability to understand most technical terms and ambiguities might also be a constraint for effective use of the ICTs media. Bhavnani, Rowena, Subramaniamand Peter (2008) believes that ICT initiatives are still out of access to rural ultra-poor and marginal farmers. Mittal and Tripathi (2009) highlighted the priority of information needed by farmers for higher adaptability of ICT based extension services 
in daily lives of farmers and argued that the ICT media would have more practicability if the content and service they deliver is in line with their information need.

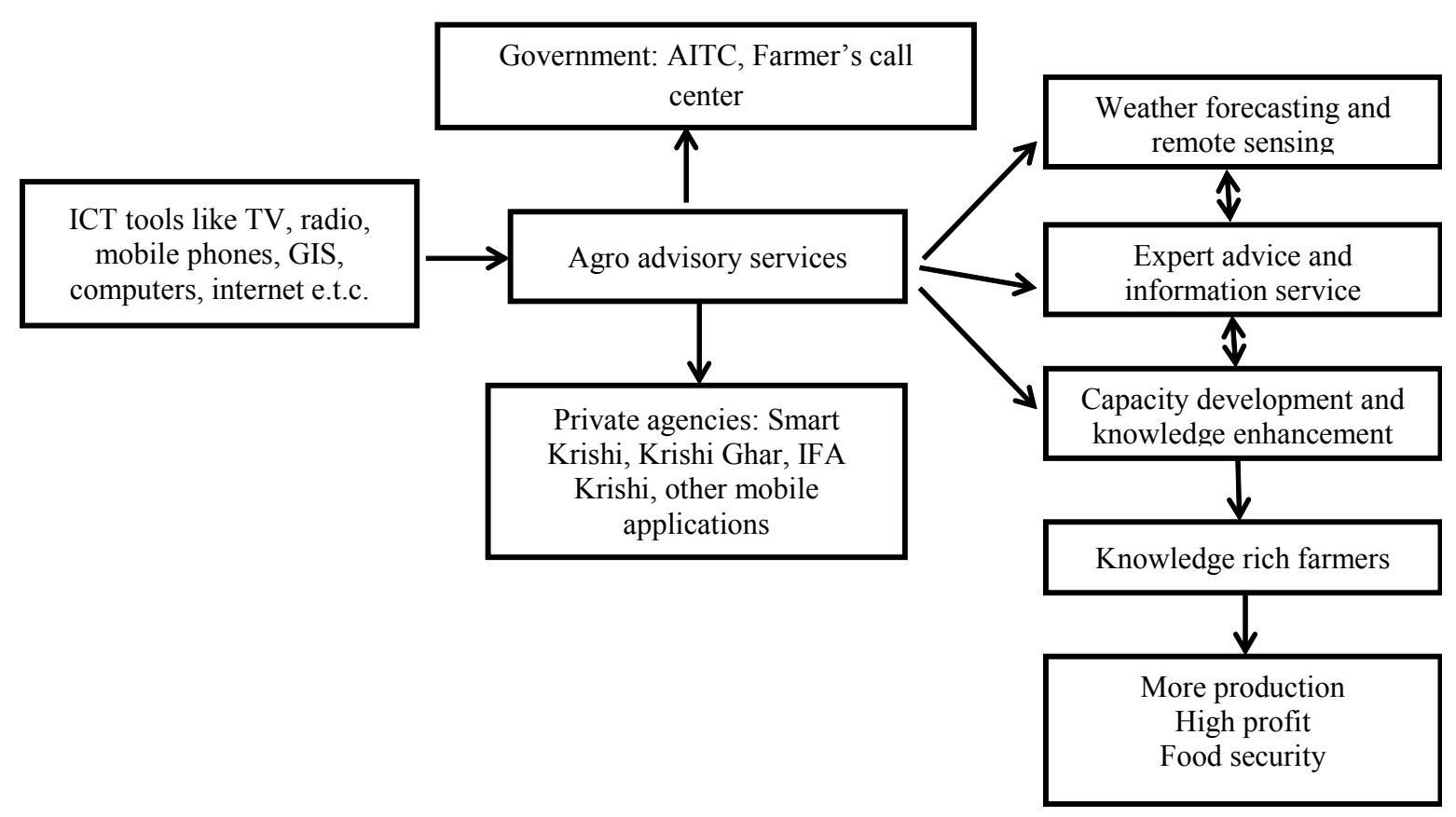

Figure 1: A model for ICT based agro-advisory service in Nepal

\section{CONCLUSION}

Although the traditional method of extension service is common in Nepal, disparity in quantity and quality of the information and barriers in technology transfer are the major reasons for its ineffectiveness. Adoption of technology for providing information to farmers can help not only to strengthen agro advisory services in Nepal but also to overcome existing problems in agriculture extension. ICT mediated agriculture education and e-Extension are some ways by which technology can be incorporated into the prevailing system of agriculture extension in Nepal. Smartphones and mobile networks can be used for live market feeds, SMS marketing, supply of practical information, forecasting etc. Web and internet are the means that has been currently used by almost all extension organization and agencies in Nepal. Although the introduction of ICTs and technology in agriculture extension process of Nepal was done recently, its effectiveness can be felt as both farmers and extension organizations are enthusiastic about this intervention. Continuity and sustainability of this innovation can always be an issue. However, improved access, equal supply, reduced cost and positive feedback from all stakeholders ensure the use of ICTs to be more attractive methods for farmers and extension works. 


\section{REFERENCES CITED}

Abraham, R. (2007) Mobile Phones and Economic Development: Evidence from the Fishing Industry in India. Information Technology and International Development, MIT Press, 4(1), 5-17.

Ali, J., \&Sushil, K. (2010) Information and communication technology (ICTs) and farmer's decisionmaking across the agricultural supply chain. International Journal of Information Management, 31(2), 149-159

Anderson, J.R., \&Feder, G. (2004). “Agricultural extension: Good intentions and hard realities. ” The World Bank Research Observer 19 (1): 41-60.

Balaji, V., Meera, S.N., and Dixit, X. (2007) ICT-Enabled Knowledge Sharing in Support of Extension: Addressing the Agrarian Challenges of the Developing World Threatened by Climate Change, with a Case Study of India. SAT e-Journal 4 (1): 18.

Best, M.L., \&Maiyer, S.G (2007) Gender, Culture and ICT use in Rural South India. Gender, Technology and Development 11(2):137-155.

Bhavnani, A., Rowena, W. W. C., Subramaniam, J., \& Peter, S. (2008) The Role of Mobile Phones in Sustainable Rural Poverty Reduction. Report.Washington, D.C., World Bank, ICT Policy Division, Global Information and Communications Department.

Cechini, S., \& Scott, C. (2002) "Can information and communication technology applications contribute to poverty reduction?Lessons from rural India."Information-Technology- for Development.10(2), 73- 84.

Das, S. (2016). Enhancing the Role of ICT in Disseminating Agricultural Information to Farmers in Bangladesh (Ph.D. thesis). University of Dhaka, Bangladesh.

FAO/WB (2000), Agricultural Knowledge and Information System for Rural Development (AKIS/ RD): Strategic Vision and Guiding Principles, Food and Agriculture Organization of the United Nations and the AKIS Thematic Group of the World Bank, Rome.

Glendenning, C. J., \&Ficarelli, P. P. (2012).The Relevance of Content in ICT Initiatives in Indian Agriculture.

Heeks. (2002). Information Systems and Developing Countries: Failure, Success and Local Improvisations. The Information Society 18, 101-112.

Kaushik, P. D. \& Singh, N. (2004) Information Technology and Broad-Based Development: Preliminary Lessons from North India. World Development, 32, 591-607

Krishi Diary. (2016). Ministry of Agricultural Development, GoN. Published by: AICC, Hariharbhawan, Kathmandu.

Mansell, R. \& When, U. (1998). Knowledge Societies: Information technology for sustainable development. Oxford: published for and on behalf of the United Nations by Oxford University Press.

Meera, S.N., Jhamtani, A., \&Rao, D.U.M. (2004) Information and Communication Technology in Agricultural Development: A comparative analysis of three projects from India. AgREN Network Paper No.135, ODI, January 2004.20p. Available at: www.odi.org.uk/agren/papers/ agrenpaper_135.pdf

Mittal, S., \&Tripathi, G. (2009).Role of mobile phone technology in improving small farm productivity. Agril Econ Res Rev 22, 451-59.

Mittal, S., Gandhi, S., \&Tripathi, G. (2010) Socio-economic impact of mobile phones on Indian agriculture. Retrieved from http://test.icrier.org/pdf/ WorkingPaper246.pdf on 15-07-2015.

Munyua, H. (2007) ICTs and small-scale agriculture in Africa: a scoping study. Final Report to International Development Research Centre (IDRC) 
Oladele, O. I. (2015). Effect of Information Communication Technology (ICT) on agricultural information access among extension officers in North West Province South Africa.South African Journal of Agricultural Extension, 43(2).

Regmi, A. (2016). Application of ICT tools in Agriculture Sector in Nepal

Richardson, D. (1997) The Internet and Rural and Agricultural Development: An Integrated Approach. Rome: FAO.

Saravanan R (2010) India. In: Saravanan R (ed) ICTs for Agricultural Extension: Global Experiments, Innovations and Experiences. Pp 115-168. New India Publishing Agency, New Delhi

Saravanan, R. (2012). ICTs for Agricultural Extension in India: Policy Implications for Developing Countries.

Silva, D., \&Ratnadiwakara, D. (2008) Using ICT to reduce transaction costs in agriculture through better communication: A case study from Sri Lanka. Colombo, Sri Lanka. Retrieved from http://www.lirneasia .net/wp-content/uploads/2008/11/transactioncosts.pdf on 23-09-2015.

Singh R., Syiem, W., Feroze, S.M., Devarani, L., Ray, L, Singh, A.K., \& Anurag, T.S. (2015). Impact assessment of mobile-based agro-advisory: A case study of tribal farmers of Ri-Bhoi district of Meghalaya. Agril Econ Res Rev 28:183-87.

Singh, M. (2014). Critical Analysis of Mobile-based Agro-advisory Services: A case of mKRISHI. (Master's thesis). IARI, New Delhi.

Sugahara. (2009). 'Traceability system for agricultural products based on RFID and mobile technology', in IFIP, International Federation for Information Processing (ed.), Computer and Computing Technologies in Agriculture II, Volume 3 (Boston: Springer), 156-62.

Suvedi, M., \&Kaplowitz, M. (2016). Feed the Future: What every extension worker should know. MEAS, USAID. Michigan State Universiy, USA.

Swanson. (2009) Changing extension paradigms within a rapidly changing global economy. European Seminar on Extension Education, Assisi, Italy.

Wankhade, A. Khare, N., \& Dhruv, S. (2011) ICT Based Kissan Mobile Sandesh-An innovative approach in Information Communication Technology for Agricultural and Rural Development Edited Book By Sarvanan C and Indira Devi T, New India Publishing Agency, New Delhi, 143-150.

World Bank (2007), Enhancing Agricultural Innovation: How to Go Beyond the Strengthening of Research Systems, Agriculture and Rural Development Department, World Bank, Washington, DC. 